\title{
FLORA DE GRÃO-MOGOL, MINAS GERAIS: STYRACACEAE ${ }^{1}$
}

\author{
AMAURI CÉSAR MARCATO \& JOSÉ RUBENS PIRANI
}

Departamento de Botânica, Instituto de Biociências, Universidade de São Paulo, Caixa Postal 11461, 05422-970 - São Paulo, SP, Brasil.

Perkins, J.R. 1907. Styracaceae. In H.G.A. Engler (ed.) Das Pflanzenreich. Wilhelm Engelmann. Berlin, 241 (Heft 30), p 1-111. SEubert, M. 1868. Styraceae. In C.F.P. Martius \& A.G. Eichler (eds.) Flora brasiliensis. Frid. Fleischer. Leipzig, vol. 7, p. 183-198, tab. 47-51.

\section{Styrax L.}

Árvores ou arbustos estrelado-tomentosos; folhas alternas. Flores em racemos axilares, actinomorfas, monoclinas; cálice gamossépalo cupuliforme, levemente denteado; pétalas 5, conatas na base, valvares; estames 10, adnatos à corola na base, tecas alongadas com deiscência longitudinal; ovário súpero, 3-carpelar, 3-locular quando jovem tornando-se subunilocular quando maduro; estilete filiforme com estigma levemente 3-lobado; semente 1, subglobosa.

1.1. Styrax camporum Pohl, Pl. bras. icon. descr. 2: 56; tab. 136. 1830.

Arbusto ca. $2 \mathrm{~m}$ alt.; folhas coriáceas, elípticas a lanceoladas, ápice acuminado, base cuneada, tomentosas na face ventral, glabras dorsalmente, 4,7-7,6 cm compr., 1,4-3,7 $\mathrm{cm}$ larg. Flor odorífera, cálice tubular, ca. $5 \mathrm{~mm}$ compr; pétalas creme, ca. 1,2 cm compr., ca. $2 \mathrm{~mm}$ larg., reflexas; filetes creme, anteras amarelas exsertas, com diminutos tri- comas estrelados ao longo da linha de deiscência; estilete alongado. (Fig. 1. A-H)

Pirani et al. CFRC 13456 (HRCB, SPF); Rossi et al. CFRC 1020 ( $\mathrm{HRCB}, \mathrm{SPF})$

Do Rio Grande do Sul à Bahia e Brasil Central, em áreas de cerrado e matas secas. Em Grão-Mogol, ocorre em carrascos, florescendo de setembro a fevereiro.

1 Trabalho realizado conforme o planejamento apresentado por Pirani et al. (2003). Bol. Bot. Univ. São Paulo 21(1): 1-24. 


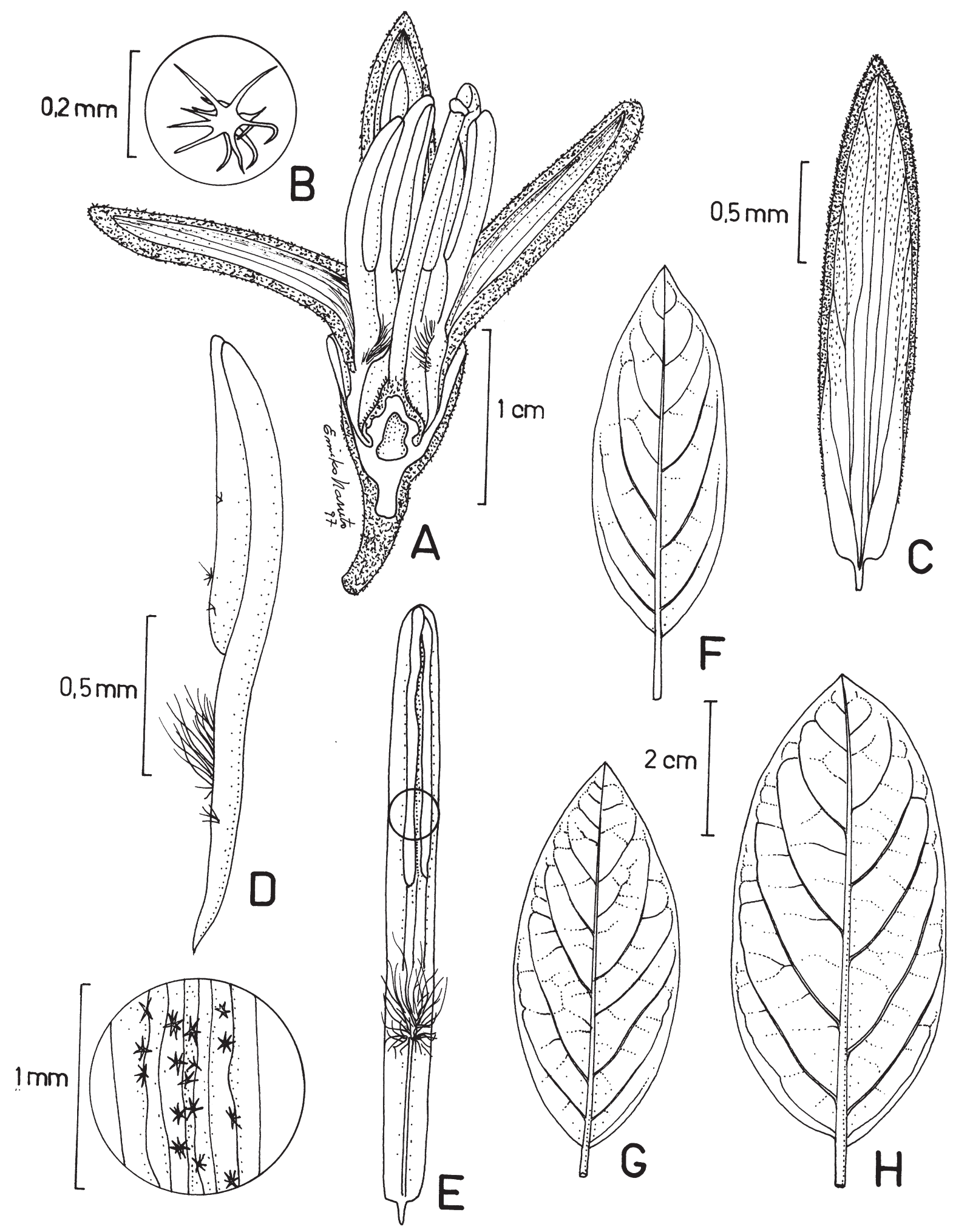

Fig. 1. STYRACACEAE. Styrax camporum. A. Flor, corte longitudinal; B. Tricoma estrelado da pétala; C. Pétala, mostrando o indumento e a nervação; D. Estame, vista lateral; E. Estame, vista frontal (no detalhe, tricomas estrelados nas tecas), F-H. Folhas, face abaxial. 